\title{
Attitude of Nurses Related to The Implementation of Patient Safety in The Intensive Care Unit
}

\section{Hanik Endang Nihayati ${ }^{1}$, Gunawan Gunawan ${ }^{2}$, Erna Dwi Wahyuni ${ }^{1}$, Sena Wahyu Purwanza ${ }^{1}$, and Hidayat Arifin 1}

${ }^{1}$ Faculty of Nursing, Universitas Airlangga, Surabaya, Indonesia

2Intensive Care Nurses, Pelindo Husada Citra Hospital, Surabaya, Indonesia

\begin{abstract}
Introduction: The error events in the Intensive Care Unit (ICU) were caused by nurses focusing more towards collaborative intervention with other medical staff and workload documentation which was not optimal. The purpose of this study was to determine the predisposing factors related to the implementation of patient safety in the ICU.
\end{abstract}

Methods: This study was a descriptive analytic correlational study. Sample size was determined by purposive sampling and obtained 26 nurses. The independent variables were the predisposing factors and the dependent variable was the implementation of patient safety. Instruments used were a questionnaire and observation sheet. Analysis was performed using Spearman's Rho and Logistic Regression.

Results: Spearman's Rho showed there was a significant correlation between knowledge $(p=0.019)$ and attitude $(p=0.040)$ towards implementation of patient safety. There was no significant of motivation $(p=0.073)$ towards the implementation of patient safety. Logistic Regression showed the dominant factor in implementation of patient safety was attitude.

Conclusion: Predisposing factors, that include knowledge and attitude, had a significant effect on the implementation of patient safety, but still required high motivation in the implementation of patient safety. In addition to knowledge and good attitude, nurses are expected to improve motivation in the implementation of patient safety.

\section{ARTICLE HISTORY}

Received: Dec 26, 2019

Accepted: Dec 31, 2019

\section{KEYWORDS}

patient safety; attitude; knowledge; attitude

\section{CONTACT}

Sena Wahyu Purwanza

$\triangle$ sena.wahyu.purwanza-

2018@fkp.unair.ac.id

$\equiv$ Faculty of Nursing, Universitas

Airlangga, Surabaya, Indonesia

Cite this as: Nihayati, H.E., Gunawan, G., Wahyuni, E.D.,, Purwanza, S.W., \& Arifin, H. (2019). Attitude of Nurses Related to The Implementation of Patient Safety in The Intensive Care Unit. Jurnal Ners, 14(3si), 345-350. doi:http://dx.doi.org/10.20473/jn.v14i3(si).17313

\section{INTRODUCTION}

Predisposing Factors on emergency patients in the Intensive Care Unit (ICU) occur in the first 48 hours. The incidence of errors in the Intensive Care Unit (ICU) is because nurses are more focused on handling and collaborating with other medical personnel so that nursing documentation is not optimal. This occurs because nurses experience an increase of workload so that they make errors when carrying out their job (Roque, Tonini, \& Melo, 2016). Error events in the ICU in terms of documentation can occur due to nurse communication (documentation) that running poorly which can caused errors in documentation that are not accordance with the standards (Nursalam, 2018).

These error events can cause Unexpected Events (UE) including misidentification of patients, errors in communication when nursing handover and receiving advice from other health workers, errors in administration of drugs, especially high alert drugs, and the incidence of infections that occur in the ICU room(Dhabi, 2008); (International, 2014);(Nursalam, 2018)). Based on data from the Ministry of Health in Indonesia the incidence of violations of patient safety carried out by nurses is $28.3 \%$ (Kementrian Kesehatan, 2013). Reports of patient safety incidents in Indonesia there were 55 cases (37.9\%) occurring in the DKI Jakarta area, while based on their type 
there was a prevalence of KNC types (Near Injury Events) as many as 69 cases $(47.6 \%), 67$ cases $(46$, $2 \%)$, and others 9 cases (6.2\%). Error events that occur in hospitals is decreasing quality of nurses due to stress caused by an increase in workload by $74 \%$ (Muthmainah, 2012).

According to the Health Ministry of Regulation Clause 8 No. 1691 of 2011 concerning Hospital Patient Safety which includes the accuracy of patient identification, improvement of effective communication, increased safety of drugs that need to be watched out, nurses ensure the right location, the right procedure, the right patient when the surgery is carried out, reduction the risk of infection related to health services, and reduction of patient falls risk. However, based on the preliminary survey data obtained by researchers in the ICU room at the PHC Hospital in Surabaya, there were still nurses who did not implement the Patient Safety Program. Preliminary data carried out by researchers in the ICU of PHC Hospital Surabaya conducted in November 2016 was obtained through observations related to patient safety actions, of the 10 morning shift nurses there were 4 who did not wash their hands before touching patients, 3 nurses did not identify patients and 3 nurses who do not put up a patient indicator of the risk of falling in bed.

Health services provided by health and non-health workers are increasingly complex along with the development of science and technology. This allows unwanted events to occur if the complexity is not managed properly. Error events occur a lot on nurses because of the high workload and collaboration with other health workers. This can cause unwanted event which can have an impact on patient safety. The consequences of patient safety that do not do correctly and precisely are the occurrence of infection in patients, errors in drug administration and interventions that can caused disability and even death in patients (Caesarityanti, 2011).

Efforts to prevent the occurrence of UE resulting in patient safety, it is necessary to make Standard Procedure Operation (SPO) and the culture of "seven steps towards patient safety" which are expected to reduce the patient's safety rate. The application of SPO in principle is part of the performance and behavior of individuals in working accordance with their duties in organization and this is usually related to the compliance of nurses in carrying out nursing actions based on SPO that has been determined. The researcher used guidelines from the implementation of Hospital Accreditation Commission patient safety in conducting observations, that is identifying of patients correctly, improving effective communication, increasing drug safety, ensuring the right location, right procedures, appropriate patients, reducing the risk of infection and reducing the risk of falls. One of the factors that influence a person's compliance is knowledge, age, education, and motivation (Notoadmodjo, 2012). This is in accordance with Lawrence Green's theory which analyzes human behavior from the level of health, which suggests that behavior is formed by several factors, one of them is predisposing factors which include knowledge, attitudes, and motivation. Based on the description above, nurses have an important role in providing comprehensive care, one of which is through the implementation of patient safety. Therefore, researchers wanted to know the predisposing factors with the implementation of patient safety in the ICU room at the PHC Hospital Surabaya.

\section{MATERIALS AND METHODS}

This study was described correlational analytic design. The population in this study were all nurse who had work in Intensive Care Unit PHC Hospital, which were 32 nurse. The sample in this study were nurse work in ICU PHC Hospital with inclusion and exclusion criteria and obtained 26 nurse. Inclusion criteria in this study include; 1 ) nurses who work in ICU PHC Hospital at least 1 year, 2) nurses who have attended patient safety socialization. While the inclusion criteria include: 1 ) nurses during maternity leave, 2) nurses who currently attending patient safety training or outside education PHC Hospital Surabaya. The sampling technique in this study used a non-probability sampling technique with the type of purposive sampling. The independent variable were the nursing factor (factor predisposing) which include knowledge, attitudes and nurses motivation, while the dependent variable was implementation of patient safety.

\section{Knowledge questionnaire}

The knowledge questionnaire in this study was about implementation of patient safety of 15 questions. If the respondent answers the question correctly, it will get a value of 1 and if the respondent answers wrongly gets a value of 0 . Then the researcher makes a classification of the level of knowledge from the respondent's answer, namely: good: 76-100 \%, sufficient: $56-75 \%$, and less: $\leq 56 \%$.

\section{Attitudes questionnaire}

The attitude instrument used in this study was a questionnaire about nurses' attitudes towards the implementation of patient safety in 30 questions. If the respondent answers correctly, he gets a score of 1 and 0 if the answers incorrect. Then, the researcher will classify the attitude classification, namely good attitude $>75$ and less good attitude $<75$.

\section{Motivation questionnaire}

The motivational instrument in this study was using a questionnaire about nurses' motivation towards the implementation of patient safety in 15 questions. Scores for positive questions: $\mathrm{SS}=4, \mathrm{~S}=3$, TS $=2$, STS $=1$. Scores for negative questions: $S S=1, S=2, T S=3$, STS $=4$. Then, researchers will classify the classification of motivation levels, namely strong motivation: $76 \%-100 \%$, moderate motivation: $56 \%$ $75 \%$ and weak motivation $\leq 55 \%$. 


\section{Instrument of patient safety implementation}

The instrument of patient safety implementation in this study uses an observation sheet about the implementation of patient safety. The number of components observed is 17 components. Respondents will get 1 score when they doing patient safety and 0 if patient safety is not done. Then, the researcher will classify the classification of patient safety implementation, which is good implementation:> $76 \%$ and less implementation $<75 \%$.

\section{Procedures}

Data collection was done by determining the population of 32 nurses in the ICU of PHC Hospital Surabaya, then selecting samples according to inclusion criteria and obtained a sample of 26 nurses, followed by sharing informed consent to respondents, then distributing questionnaires to a sample of 26 respondents in the room ICU Surabaya PHC Hospital. The questionnaire was distributed at the time of respondent's rest hour, then the respondent was asked to fill out the questionnaire accompanied by the researcher so that there was no bias (cheat sheet when filling out the questionnaire). After the results were obtained from the questionnaire, then the researchers began to observe at least 2 nurses related to the implementation of patient safety which includes the accuracy of patient identification, increased effective communication, increased drug safety to watch out for, nurses ensure the right location, right procedure, right patient before surgery, reduction the risk of infection related to health services, and reduction of the risk of falling patients performed in the ICU PHC Hospital in one shift as much as twice, so that researchers make observations on morning or afternoon shifts.

\section{Analysis}

This study uses a data analysis test to analyze related factors to the implementation of patient safety programs in the ICU room at PHC Surabaya Hospital. The scale obtained is ordinal through a questionnaire. The data obtained will be collected and analyzed by statistical tests using the Spearman Rank (Rho) correlation test to determine whether there is a relationship between predisposing factors and the implementation of patient safety. The basis of decision making is based on 95\% confidence level or $\alpha=0.05$.). The strength of the relationship is expressed in the magnitude of the coefficient correlation $\mathrm{p} \leq \alpha(0.05)$ which means that there is a meaningful relationship between the two measured variables, namely predisposing factors with the implementation of patient safety. If $p \leq \alpha(0,05)$ then $\mathrm{H} 0$ is rejected and $\mathrm{H} 1$ is accepted.

\section{Ethical consideration}

This research will begin by carrying out several procedures related to research ethics including informed consent, anonymity, confidentiality. The committee of ethical approval in the Faculty of
Nursing Universitas Airlangga give approved the above mentioned protocol with number 264-KEPK.

\section{RESULTS}

The results of the knowledge of respondents with the implementation of patient safety from 26 respondents. The majority of respondents' knowledge with sufficient knowledge categories can do patient safety in a good category. However, there are still respondents with sufficient knowledge in the implementation of patient safety is still not good. The results show there are respondents with less knowledge, but in the implementation of good patient safety.

The relationship between the level of respondents 'knowledge about patient safety towards the implementation of patient safety and the Spearmen's Rho test shows that there is a relationship between respondents' knowledge of the implementation of patient safety in the Intensive Care Unit (ICU) in PHC Surabaya Hospital with a moderate correlation level and a positive correlation coefficient indicating that there is a relationship between the variable that is in the same direction with the same high value.

The results of the attitudes of respondents with the implementation of patient safety from 26 respondents. The majority of respondents with good attitude in the implementation of patient safety are also good. Meanwhile, there are respondents with a bad attitude, but in the implementation of patient safety in the good category.

The relationship of the respondent's attitude towards the implementation of patient safety with the spearmen's rho test shows that there is a relation between the respondent's attitude towards the implementation of patient safety in the Intensive Care Unit (ICU) Room of PHC Hospital with a moderate correlation level and a positive correlation coefficient that shows the relationship between the two variables in the same direction the same height value.

The results between the motivations of respondents with the implementation of patient safety from 26 respondents. The majority of respondents with strong motivation in implementing patient safety are in a good category, but there are still respondents with strong motivation, but with poor implementation of patient safety.

The relationship of respondents 'motivation towards the implementation of patient safety with the Spearmen's Rho test showed that there was no correlation between respondents' motivation towards the implementation of patient safety in the Intensive Care Unit (ICU) Room of the Surabaya PHC Hospital with a low correlation level and a positive correlation coefficient that showed a relation between two directional variables with the same high value.

The results of candidate selection were carried out using a simple logistic regression test. The requirement to enter the multivariate analysis model 
Table 1. Distribution of Results between the Categories of Knowledge and Implementation of Safety Patient

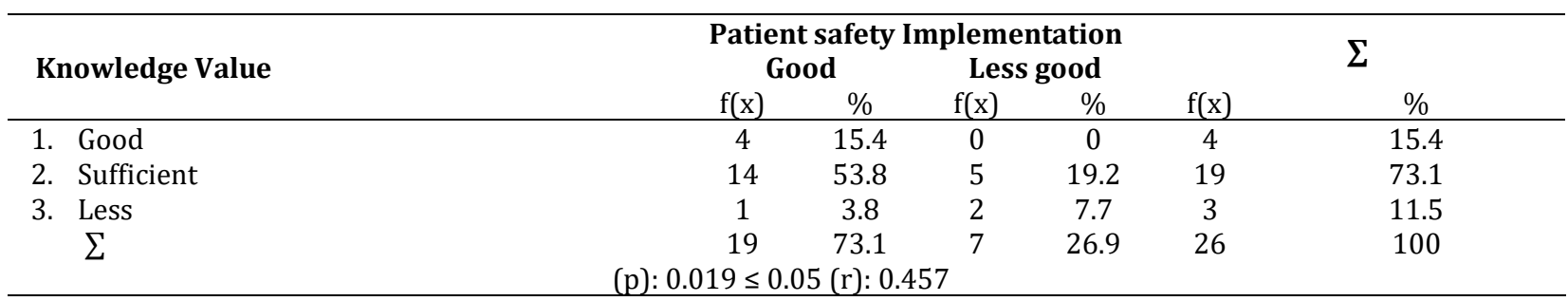

Table 2. Results Distribution between Attitude Categories and Implementation of Safety Patient

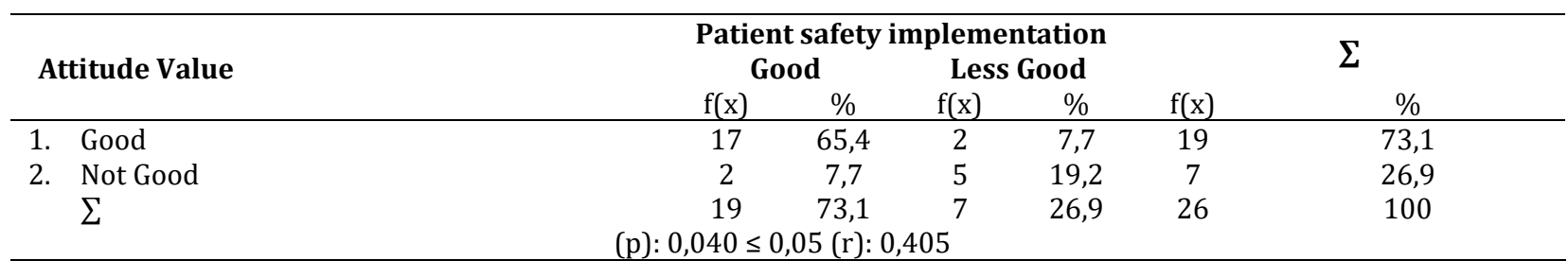

Table 3. Results Distribution between Motivation Categories and Implementation of Safety Patient

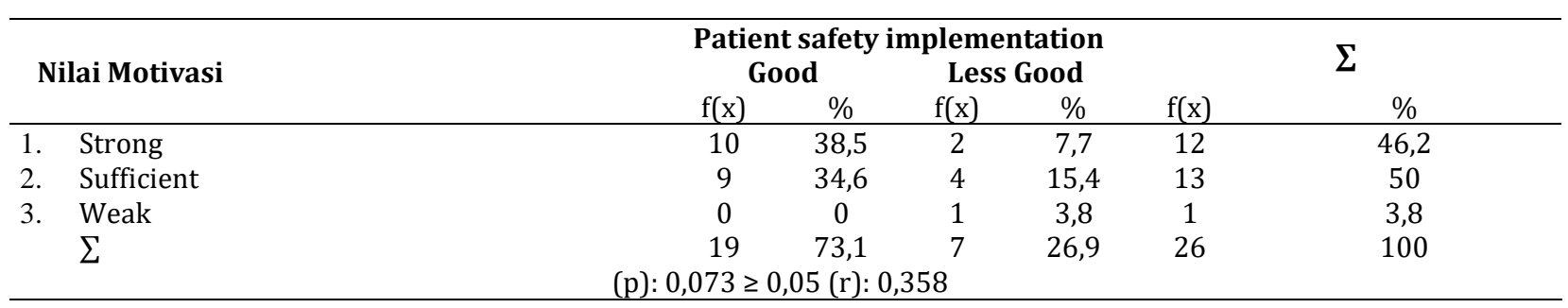

Table 4. Factors predisposing Distribution of candidate selection to the implementation of patient safety

\begin{tabular}{cc}
\hline Variable & $p$-value \\
\hline Knowledge & 0,082 \\
Attitude & 0,006 \\
Motivation & 0,147 \\
\hline
\end{tabular}

Table 5. Significant Levels of Independent Variables Against Dependent Variables Distribution

\begin{tabular}{lccc}
\hline Predisposing Factor & Wald & p-value & OR \\
\hline Knowledge & & & 1.507 \\
Attitude & 0.93 & 0.760 & 13.940 \\
Motivation & 3.811 & 0.051 & 2.166 \\
Constant & 0.527 & 0.468 & .002 \\
\hline
\end{tabular}

is $p$-value $\leq 0.25$. The results show that predisposing factors (knowledge, attitude, and motivation) meet the requirements to enter the multivariate analysis model.

The results showed that attitude was the most influential factor with the implementation of patient safety in the Intensive Care Unit (ICU) Room of the Surabaya PHC Hospital 13,940 times influential in patient safety implementation.

\section{DISCUSSION}

Respondents' knowledge about patient safety in the Intensive Care Unit (ICU) Room of the Surabaya PHC Hospital was mostly at a sufficient level, but there were also those who lacking knowledge. The more advanced of science and technology that continues to evolve, the learning process to increase knowledge must be continue. The Intensive Care Unit (ICU) is equipped with adequate mechanical facilities and equipment, so that the existence of respondents as health workers must really master the operation of tools, care, willingness to always learn to increase knowledge and creativity and change the behavior of respondents as health workers in the better direction is needed in the implementation of patient safety. 
Knowledge or cognitive is a very important domain in the formation of a person's actions (overt behavior). Knowledge is defined as intellectually knowledge with facts, truths / principles added to observations, and experiences and reporting (Notoadmodjo, 2012). The learning process is not only directly obtained from formal education or informal education. Lack of knowledge can be caused by the process of acceptance and understanding of the information obtained that still not maximal. One of the way that can be done to increase knowledge that is useful is, doing conducting socialization to improve the effectiveness in achieving the work results set for safety and satisfaction. Patient safety socialization is included in the policy of implementing patient safety at Surabaya PHC Hospital through education, training and research.

The results of research conducted by researchers showed a significant relation between attitudes towards the implementation of patient safety. This is supported by data distribution of attitude categories which shows that most respondents have good attitude towards the implementation of patient safety, as well as length of work data majority of the respondents have working experience for 6-10 years, so that they have enough experience in implementing patient safety. However, there are still some respondents in the sufficient category during the implementation of patient safety, this may be influenced by culture, quality of life, influence of people who are considered important, or may be influenced by the personal experience of respondents based on the length of time in the Intensive Care Unit (ICU) Surabaya PHC Hospital.

Lawrence Green's (1980) theory which states that one of the factors that influence behavior is attitude as a predisposing factor. Walgito (2003) expressed his opinion that in order to change attitudes, people generally will change their cognitive components first so that the affective component will eventually change. Some other factors that influence attitudes according to are personal experience, culture, other people who are considered important, mass media, educational institutions or institutions, religion, and individual factors (Azwar, 2002).

Data distribution of respondents' motivation categories obtained by researchers shows that the majority of respondents' motivation are in the sufficient category, and most of the respondents' motivation is in the strong category. This is very different from the opinion which says that good motivation will be followed by a change in good attitude, in this case the implementation of patient safety. Meanwhile, respondents' motivation was good but there was no relationship with the implementation of patient safety in the Intensive Care Unit (ICU) Room of the PHC Hospital in Surabaya.

This can be caused by respondents show different performance in providing nursing services due to motivation. This is also included in the implementation of patient safety. Respondents are motivated by physiological needs, safety, attention and love, self-esteem and self-actualization. Respondents were also affected by co-cognitive needs for knowledge (Kanagasabai, 2013). According to the theory of needs, the motivation of someone comes when they have not reached a certain level of satisfaction in their lives. Satisfied needs will no longer be a motivator.

The results of the analysis using multiple logistic regression tests showed that attitude was the most influential factor with the implementation of patient safety in the Intensive Care Unit (ICU) Room of the Surabaya PHC Hospital with 13,940 influential times in the implementation of patient safety. Lawrence Green's (1980) theory which states that factors that influence behavior one of them is attitude as a predisposing factor. Zimbardo \& Ebbesen in Ahmadi (1999) states that attitudes are a predisposition to an individual, an object that contains components - cognitive, affective, and behavioral components. The limitations of this study are that questionnaires from questionnaires conducted by respondents were directed by the researcher directly, allowing respondents to experience pressure when filling out questionnaires, as well as data retrieval techniques carried out in a momentary manner, making it less representative of the research results.

\section{CONCLUSION}

Predisposing factors (knowledge and attitude) have a significant relationship with patient safety implementation in Intensive Care Unit (ICU) Room PHC Hospital Surabaya. But good predisposing factors (motivations) do not necessarily influence the implementation of patient safety in Intensive Care Unit (ICU) Room PHC Hospital Surabaya, this can be caused by several factors such as knowledge and length of work experience. The most dominant and influential predisposing factor of the implementing patient safety is the attitude of nurses. The implication of the research to increase patient safety implementation and quality nursing care. 


\section{REFERENCES}

Azwar, S. (2002). Sikap Manusia, teori dan Pengukurannya. Yogyakarta: Pustaka Pelajar.

Caesarityanti, A. . (2011). Faktor Predisposing Yang Berhubungan Dengan Pelaksanaan Patient safety Di Ruang Hemodialisa. Universitas Airlangga.

Dhabi, H. A. A. (2008). Hospital Standart. Abu Dhabi: Health Authority.

International, J. C. (2014). Joint Commission International Accreditation Standards for Hospital 5th Edition.

Kanagasabai, P. S. (2013). Effect of Multisensory Stimulation on Neuromotor Development in Preterm Infants. Indian J Pediatr, 6(80), 460464. https://doi.org/10.1007/s12098-0120945-z
Kementrian Kesehatan, R. (2013). Riset Kesehatan Dasar 2013. Jakarta.

Muthmainah, I. (2012). Faktor - Faktor Penyebab Stres Kerja di Ruangan ICU Pelayanan Jantung Terpadu Dr. Cipto Mangunkusumo Jakarta. Universitas Indonesia.

Notoadmodjo, S. (2012). Promosi Kesehatan dan Perilaku Kesehatan. Jakarta: Rineka Cipta.

Nursalam. (2018). Manajemen Keperawatan Aplikasi dalam Praktik Keperawatan Profesional (5th ed.; P. Lestari, Ed.). Jakarta: Salemba Medika.

Roque, K. E., Tonini, T., \& Melo, E. caetano P. (2016). Adverse Events in the Intensive Care Unit: Impact on Mortality and Length of Stay in a Prospective Study. Cad. Saúde Pública, Rio de Janeiro, 32(10). https://doi.org/e00081815 